\title{
Possibilidades pedagógicas na perspectiva de uma educação online (** $^{\text {* }}$
}

\author{
Andreson Lopes de Lacerda ${ }^{1}$ \\ Mestrando do Programa de Pós-Graduação em \\ Educação Científica e Tecnológica - UFSC \\ Tatiana da Silva ${ }^{2}$ \\ Departamento de Física - UFSC \\ Florianópolis - SC
}

\section{Resumo}

No presente, muitas são as possibilidades que os professores têm em mãos para melhorar sua prática. As mais recentes tecnologias digitais abriram novas perspectivas para o ensino e a aprendizagem das ciências em geral e, particularmente, da Física. Dentre essas tecnologias estão os ambientes virtuais de aprendizagem (AVA) que ampliaram as possibilidades e iniciativas de produção de cursos, disciplinas e atividades baseadas no contexto online. É nesse cenário, portanto, que esse artigo se estabelece. Sugere-se o design instrucional como contribuição para a elaboração de estratégias de aprendizagem em AVA. Os resultados apresentados buscam aproximar, numa perspectiva integradora, os pressupostos norteadores adotados frente às tecnologias para o ensino de Física, particularmente, apoiados por um ambiente virtual de aprendizagem, e este por sua vez como apoio a uma sala de aula presencial. $O$ material resultante dessa investigação busca estabelecer múltiplas conexões com o espaço virtual e garantir a articulação de cada material com os demais do mesmo conjunto, furtando-se de estabelecer uma proposta fragmentada e descontextualizada do programa da disciplina.

Palavras-chave: Ensino presencial de física; Ambiente Virtual de Aprendizagem; Design instrucional.

\footnotetext{
${ }^{+}$Pedagogical possibilities from the perspective of an online education

* Recebido: dezembro de 2013. Aceito: julho de 2014.

1 E-mail: andrelopescg@gmail.com

2 E-mail: silvatat@gmail.com
} 


\begin{abstract}
The latest digital technologies have opened new perspectives on teaching and learning of science in general, and particularly in Physics. The emergence of virtual learning environments (VLE) expanded the possibilities and initiatives to the implementation of courses, classes, and activities based on the online context. Therefore, this article is set in this scenario. The instructional design as a contribution to the development of learning strategies in VLE is suggested. The results of the study aim to approach, in an integrative perspective, the guiding assumptions adopted in the face of technologies for Physics teaching, particularly supported by a virtual learning environment, and this, in turn, supports face to face classes. In this sense, the material resulting from this research seeks to establish multiple connections to the virtual space, and ensure linkage of each material with others from the same set, avoiding the establishment of a fragmented and decontextualized proposal of the discipline content.
\end{abstract}

Keywords: Teaching Physics classes; Virtual Learning Environment; Instructional Design.

\title{
I. Introdução
}

$\mathrm{O}$ acesso amplo às informações e saberes disponíveis na Internet, os recursos e as ferramentas disponíveis podem ser entendidas como oportunidades de ampliação das possibilidades pedagógicas da prática docente e, consequentemente, a abertura de caminhos profícuos para melhorias na aprendizagem.

No presente, muitas são as possibilidades que os professores têm em mãos para melhorar sua prática. As informações que os alunos recebem através de vários suportes midiáticos: livros, revistas, televisão, jornais, Internet e demais formas hipermidiáticas de comunicação podem servir como ponte para a legitimação dos saberes científicos. Moran (2001) e Souza, de Bastos e Angotti (2001) ressaltam que um dos desafios é de como transformar a informação em conhecimento e em sabedoria. O desafio está em construir junto com o aluno uma visão crítica das informações que circulam e adequá-las ao discurso científico e aos conceitos formais. Tal desafio pode significar um paradigma no plano educacional.

O professor em meio a esse cenário deve incorporar o novo, selecionar e planejar as atividades de aprendizagem de modo a envolver os alunos em uma comunidade de investigação, valorizando as contribuições de cada um, estimulando a confiança para o trabalho colaborativo e individual e respeitando os diversos ritmos de aprendizagem.

A utilização das Tecnologias Digitais de Informação e Comunicação (TDIC) no âmbito da educação como instrumento de mediação pedagógica pode ser problematizada na 
perspectiva da educação online, que pode implicar maior ou menor separação de tempo e de espaço, maior ou menor interação face a face e maior ou menor conexão em rede. Uma ação sistemática que abrange redes de comunicação, hipertextos e hipermídias, tendo como principal característica a mediação tecnológica pela conexão em rede.

Quando se trata de ensino de Física são comuns os relatos sobre as dificuldades relacionadas à apreensão de conceitos básicos das temáticas dessa área, particularmente, por se tratarem de assuntos com alto grau de abstração, com formas de pensar pouco habitual para os estudantes (SILVA; BARROSO, 2008). As discussões oriundas de pesquisas e relatos de experiências de professores e estudiosos da área propõem como alternativa para auxiliar na diminuição desse hiato no processo ensino-aprendizagem, a introdução e a integração às práticas educativas tradicionais, recursos tecnológicos e digitais com possibilidades pedagógicas para o ensino de Física.

É legítima, portanto, a elaboração de um exercício investigativo que tenha como objeto a educação mediada por tecnologias, estudada a partir de diferentes conjuntos e aparatos midiáticos. Nessa perspectiva propõe-se um olhar sobre os Ambientes Virtuais de Aprendizagem e suas características quando se pressupõe a realização de práticas pedagógicas em educação online. Nesse sentido, é conveniente que propostas de utilização de interfaces digitais em sala de aula presencial, particularmente, AVA sejam apresentadas e seus resultados sejam validados.

Não se trata aqui de bancar a aposta em um determinismo tecnológico, que venha considerar as TDIC, e consequentemente as ferramentas e recursos dos AVA, como fatores únicos determinantes daquilo que se entende como melhorias no processo ensinoaprendizagem. Mas sim de tentar compreender com clareza, o papel que desempenham no redimensionamento da prática docente e das possibilidades e potencialidades que possuem para promover práticas mais dinâmicas e flexíveis para melhor lidarmos com essa realidade. A premissa é a de que desenhado adequadamente, o AVA pode se tornar um campo fecundo para a realização de situações e estratégias de aprendizagem que tirem melhor proveito dos seus recursos. Nesses espaços aumenta-se a interatividade, a ação responsiva e intensifica-se a bidirecionalidade. Torna-se possível a troca de resultados onde o professor e os alunos podem comparar e discutir fontes de informação, os alunos podem relatar suas descobertas e socializar suas dúvidas e os resultados de atividades.

Embora não se pretenda excluir a possibilidade de que os AVA sejam utilizados como repositórios de conteúdos, busca-se nessa pesquisa, evidenciar que suas ferramentas possuem potencialidades e possibilidade pedagógicas. É nessa perspectiva que o design instrucional pode contribuir, no sentido de valorizar os recursos existentes nos ambientes virtuais de aprendizagem oferecendo-lhes oportunidades para potencializar a comunicação, o ensino e a aprendizagem.

As discussões aqui apresentadas são decorrentes do trabalho de pesquisa de uma dissertação de Mestrado realizada no Programa de Pós-Graduação em Educação Científica e 
Tecnológica (PPGECT) da Universidade Federal de Santa Catarina (UFSC), e, portanto, o conteúdo desse artigo representa um recorte de seus resultados.

\section{Diversidade de elementos e o desafio de integrá-los}

No ensino presencial, os AVA têm sido aproveitados como espaços para mediação pedagógica em disciplinas de graduação, em aulas de reforço para alunos em dependência, ambientes colaborativos em cursos de pós-graduação, extensão, especialização e formação de professores. Na Universidade Federal de Santa Catarina (UFSC) a utilização dos AVA como apoio ao ensino presencial, vem sendo realizada desde 2009, em virtude da oferta de cursos na modalidade a distância.

Os recursos didáticos baseados na linguagem hipermídia, com alto grau de interatividade e apoiados nas ferramentas da Internet, por exemplo, podem ajudar na visualização dos fenômenos físicos e na compreensão das relações matemáticas envolvidas. Como afirmam Medeiros e Medeiros (2002) os materiais didáticos digitais podem ajudar a ver e a interagir com os modelos científicos subjacentes, a desenvolver habilidades de raciocínio crítico, a fornecer feedback para desse modo aperfeiçoar a compreensão dos conceitos envolvidos, a acentuar a formação dos conceitos e a promover a mudança conceitual.

Com efeito, apontam-se os AVA como espaços que permitem que essas possibilidades ocorram. Conjectura-se aqui que possuem potencialidades para contemplar diversos aspectos relacionados ao ensino e à aprendizagem. No entanto, para que o seu potencial configure-se em possibilidades de ganhos no ensino e na aprendizagem é preciso que sejam desenvolvidas estratégias adequadas aos objetivos de ensino e aos recursos disponíveis nos AVA. Estas delineadas sob a égide de um desenho capaz de considerar aspectos que vão desde a compreensão da estrutura dessas estratégias, até a maneira como os conteúdos podem ser apresentados, recebidos e processados.

Sugere-se, portanto, o design instrucional (DI) como um aliado para o desenho didático de um AVA. O DI deve ser entendido como uma ação de planejamento de estratégias de aprendizagem desenvolvidas para contextos distintos, que vão desde unidades de ensino até cursos inteiros. Seus fundamentos são influenciados por diversos campos do conhecimento e os saberes construídos por outras áreas passaram a ser integrados de maneira a auxiliar na proposição da linguagem e de interfaces adequadas, levando-se em consideração características inerentes ao processo de instrução que favorecem a aprendizagem.

A partir dessas ideias iniciais, é possível delinear o que esta pesquisa propõe explorar. Destaca-se se aqui uma diversidade de elementos a serem considerados. Têm-se os AVA como espaços de aprendizagem, tem-se o DI como um parceiro para auxiliar na elaboração de estratégias e para a sua consequente estruturação e tem-se o ensino de Física que pode ter seus conceitos e temáticas trabalhados à luz dos recursos digitais.

O grande desafio da educação online não está centrado unicamente na disponibilização de ambientes e interfaces para utilização nos diferentes espaços educativos, mas sim na 
compreensão destes artefatos como potencializadores de práticas pedagógicas que permitam aos alunos interações e possibilidades de construção do conhecimento.

\section{Caminhos e procedimentos para a investigação}

O cenário investigativo adotado foi o ensino de física mediado por AVA, particularmente, uma disciplina ofertada para um curso presencial da UFSC. Ela tem como objetivo conduzir o aluno a adquirir uma visão conceitual sobre eletrodinâmica, ondas, ótica, relatividade e mecânica quântica. Pretende-se, ao final da disciplina, que o aluno seja capaz de fazer cálculos simples utilizando ferramentas da teoria ondulatória, da termodinâmica básica, da relatividade e da física quântica. Os conteúdos abordados e elencados na ementa da disciplina em questão, bem como outros aspectos relacionados a ela podem ser encontradas em Lacerda (2013).

Diante do exposto, definiram-se os procedimentos adequados para planejar um design instrucional coerente com os objetivos da disciplina e para todos os conteúdos do seu programa. Para tanto, recorreu-se inicialmente a uma revisão da literatura sobre ambientes virtuais de aprendizagem e design instrucional que resultou na identificação de elementos necessários para o desenho da disciplina. Inferiu-se que é recomendada a utilização de modelos para a estruturação e elaboração de estratégias de aprendizagem para que se possa explorar o potencial pedagógico de um AVA (LACERDA; SILVA, 2012; 2013).

A pesquisa foi realizada no primeiro semestre de 2012, período que compreendeu a aplicação da proposta, coleta e análise dos dados. Dentre os instrumentos utilizados um questionário de avaliação do ambiente virtual da disciplina, disponibilizado online.

\section{Desenho da disciplina}

Considera-se que o design instrucional contribui para uma melhor estruturação dos conteúdos, na criação de materiais didáticos em linguagem diversificada e na elaboração de estratégias de aprendizagem em um AVA. Então, para propor um desenho pedagógico é preciso considerar não somente sua estrutura tecnológica, mas, principalmente, sua potencialidade pedagógica. Demonstra-se que é possível fazê-lo a partir de pressupostos teóricos ancorados no modelo escolhido. Os resultados que aqui se apresentam buscam, numa perspectiva integradora, aproximar os pressupostos norteadores adotados frente às tecnologias para o ensino de Física, particularmente, apoiados por um ambiente virtual de aprendizagem, e este por sua vez com apoio a uma sala de aula presencial.

O Moodle oferece diferentes opções de organização das informações, uma delas é a estrutura de tópicos. Nesse trabalho, organizou-se o AVA em 7 tópicos, um (1) para as informações gerais da disciplina onde se disponibilizam o plano de ensino, o horário de atendimento da professora e dos monitores, o cronograma das provas e um (1) para cada conteúdo (Ondas Mecânicas, Ondas Eletromagnéticas, Ótica, Termodinâmica, Relatividade Restrita e Me- 
cânica Quântica) contemplando-se as atividades, o material didático produzido e outros materiais de apoio, tais como: notas de aula, vídeos, simuladores e listas de exercício. O material completo está disponível para acesso no Moodle, através do link: $<$ https://moodle.ufsc.br/course/view.php?id=30608>.

No que concerne à adequação das estratégias, o AVA foi desenvolvido adotando-se um modelo que propõe o fluxo das estratégias sob a égide de quatro eventos instrucionais: preparação, atividades de aprendizagem, interação e transferência (ALLY, 2004). O segundo e terceiro eventos são vistos como um único evento associado à prática. A sua organização e apresentação foi desenvolvida segundo os princípios da teoria da carga cognitiva (SWELLER; VAN MERRIENBOER; PAAS, 1998; SANTOS; TAROUCO, 2007; JONG, 2010) e a linguagem escolhida para a interface de navegação foi a hipermídia. Quanto à exploração dos quatro eventos instrucionais, entende-se que é possível de acordo com o conteúdo e os objetivos de aprendizagem, adotar mais profundamente um dos eventos e em outro conteúdo aprofundar-se em outra, sem seguir o modelo em sua completude. Tal escolha se justifica quando o conteúdo da disciplina é extenso e pouco uniforme, como é o caso da disciplina em questão. No entanto, chegamos a essa conclusão após a implementação de um estudo piloto no segundo semestre de 2011 no qual se adotou apenas um dos conteúdos da disciplina, o de Relatividade Restrita que aplicou o modelo em sua plenitude e no primeiro semestre de 2012 ampliamos para toda a disciplina.

Outra estratégia adotada foi a de primeiro fazer com que os estudantes se familiarizassem com uma proposta de trabalho que não se ancora apenas no tempo de sala de aula e às diferentes ferramentas do AVA, para depois utilizá-la em sua plenitude. Optou-se também em elaborar atividades obrigatórias e não obrigatórias para avaliar o uso do ambiente a partir da participação dos alunos. Assim, tinha-se em mãos um ambiente virtual de aprendizagem flexível, com atividades adaptáveis ao ritmo do grupo de modo a serem incorporadas de acordo com a demanda. As atividades não obrigatórias evidentemente não fizeram parte do método da avaliação da disciplina.

\section{Ondas Mecânicas}

O DI desse conteúdo tinha em mãos a possibilidade de criar liames entre a proposta do professor em sala de aula (seus objetivos e suas abordagens) e as proposições no AVA. Optou-se de início apresentar a importância do conceito de onda para a ciência e para presença das ondas no dia-a-dia dos alunos por intermédio de um link para uma página da Internet. Elaborou-se também um texto introdutório no tópico destinado a tal conteúdo com os principais objetivos que norteavam o estudo do conteúdo e que estariam presentes ao longo de toda a disciplina, desde a linguagem essencial utilizada para a descrição do conceito, a formulação básica das ondas mecânicas até a utilização do conceito de ondas para descrição pela mecânica quântica das partículas subatômicas. As principais definições sobre o conteúdo e suas aplicações foram disponibilizadas utilizando-se a ferramenta Livro (Book) do Moodle. Tal estra- 
tégia tornaria o conteúdo mais familiar ao aluno, através da linguagem hipermidiática e, consequentemente, possibilitaria a ele visualizar o fenômeno, bem como a linguagem matemática que lhe é peculiar. Elaborou-se também um questionário, com questões de múltipla escolha para que o aluno pudesse refletir sobre o que havia apreendido, seja nas leituras dos Books, seja nas aulas expositivas do professor.

Para a prática dos conceitos foram elaboradas duas atividades semipresenciais. Uma das atividades utilizava a ferramenta Tarefa do Moodle, onde o aluno deveria enviar um arquivo com a sua resolução. O objetivo era explorar a relação entre a linguagem matemática e representações gráficas. Para isso, deveriam escrever a função de uma onda mecânica unidimensional transversal cujos parâmetros físicos seriam definidos por eles (comprimento, velocidade, amplitude, entre outros) e construir o gráfico da potência instantânea em função do tempo. Tinha-se aqui a possibilidade de tornar o aluno produtor e autor da significação que o conteúdo lhe proporciona ao mesmo tempo em que forneceu a oportunidade para participar ativamente da realização da sua tarefa, por exemplo, propondo o enunciado do próprio exercício, busca por softwares de elaboração de gráficos da sua preferência. Após a realização da tarefa proposta, ele também foi convidado, numa ação responsiva, a discutir e a explicar os resultados obtidos a partir da tarefa de sua autoria.

Outra atividade elaborada lançou mão da ferramenta Glossário, que permite ao aluno criar e manter uma lista de termos ou definições no formato de dicionário. Tal módulo de atividade também fomenta a avaliação entre pares e a colaboração quando se habilita o espaço para comentários no qual os demais participantes podem redefinir as contribuições dos colegas, buscando-se construir em parceria uma definição. Na atividade solicitou-se que os alunos incluíssem a definição de algum termo, palavra ou expressão usada nos conteúdos referentes a ondas mecânicas. Disponibilizou-se também um espaço para comentários que convidava o aluno a contribuir no aperfeiçoamento do conceito ou expressão definido pelo colega. Tal estratégia, por exemplo, pode ser utilizada no início do curso para identificar os conhecimentos dos alunos e ao final do curso para que possa, após as discussões, leituras, resolução de exercícios, reformular aquela definição apresentada no início das atividades. Por suas características pode ser uma preciosa ferramenta de diagnóstico para o professor.

Para aproximar o conceito de ondas à realidade do aluno contextualizou-se o conceito de ondas mecânicas, sua propagação e suas grandezas escolhendo-se o tema "Tsunamis". Para tanto, utilizou-se a ferramenta Lição que oportuniza disponibilizar esse conjunto de atividades em um só espaço, constituída de uma página com um enunciado que levava o aluno a pensar sobre a transferência do enfoque dado em sala de aula, que trata somente das ondas em cordas propagando-se em uma dimensão para uma onda mecânica marítima, os tsunamis. Após ler o enunciado, o aluno deveria responder a uma questão de múltipla escolha. Em seguida era direcionado a um artigo de divulgação científica sobre o tema em questão, caso marcasse a resposta errada. 
Ainda com o objetivo de aproximar o conteúdo da realidade dos alunos e com enfoque no tema "Ondas Marítimas", propôs-se aos alunos uma atividade de pesquisa, na qual eram orientados por algumas questões, a perceberem como a descrição matemática para a velocidade de propagação das ondas em cordas é alterada para se descrever ondas marítimas em águas rasas e em águas profundas. Também, sugeriu-se que os resultados da pesquisa fossem socializados com os demais colegas utilizando-se a ferramenta "Base de Dados", cuja característica é levar os participantes a criar um banco de dados de entradas de registros, nos quais podem ser inseridos imagens, arquivos e textos, a mantê-lo e a pesquisar nele.

A partir da descrição acima se observa que foi possível propor estratégias para todos os eventos instrucionais do modelo adotado.

\section{Ondas Eletromagnéticas}

No conteúdo de ondas eletromagnéticas tinha-se em questão que se tratava de um tipo de onda "não palpável", entretanto, presente no dia a dia de todos nós. Desse modo, elaborou-se um Quiz na ferramenta Questionário para identificar os conhecimentos prévios dos alunos sobre a temática. Tal estratégia de preparação seria retomada em outro momento para verificar o entendimento dos alunos depois das leituras, das aulas expositivas e da resolução de alguns exercícios. Cabe ressaltar, que esse tipo de estratégia busca auxiliar o professor na condução das aulas, bem como o aluno a se familiarizar com as questões que envolvem o conteúdo a ser apreendido. Por isso, é importante que a atividade elaborada seja de fácil compreensão e que se aproxime da realidade dos alunos e, para isso, fez-se uso também de imagens.

Durante o processo de planejamento e desenvolvimento das atividades, observou-se um grande número de material didático em formato digital sobre ondas eletromagnéticas disponíveis na Internet, tais como: simuladores, animações, imagens e vídeos. Os materiais selecionados auxiliaram na criação do material de leitura a serem disponibilizados nos books, tornando possível estabelecer múltiplas conexões ao conteúdo e também aproximá-lo da realidade dos alunos. Nesse sentido, pode-se citar como exemplo a conexão entre ondas eletromagnéticas e radiações solares, prejudiciais à saúde. A Fig. 1 apresenta um dos textos criados nessa perspectiva e que conduzia o aluno, após a leitura, a assistir um vídeo sobre as tempestades solares. Buscava-se a reflexão do aluno sobre tais questões e consequentemente o estímulo à discussão, seja com seus colegas ou mesmo com o professor em sala de aula. 


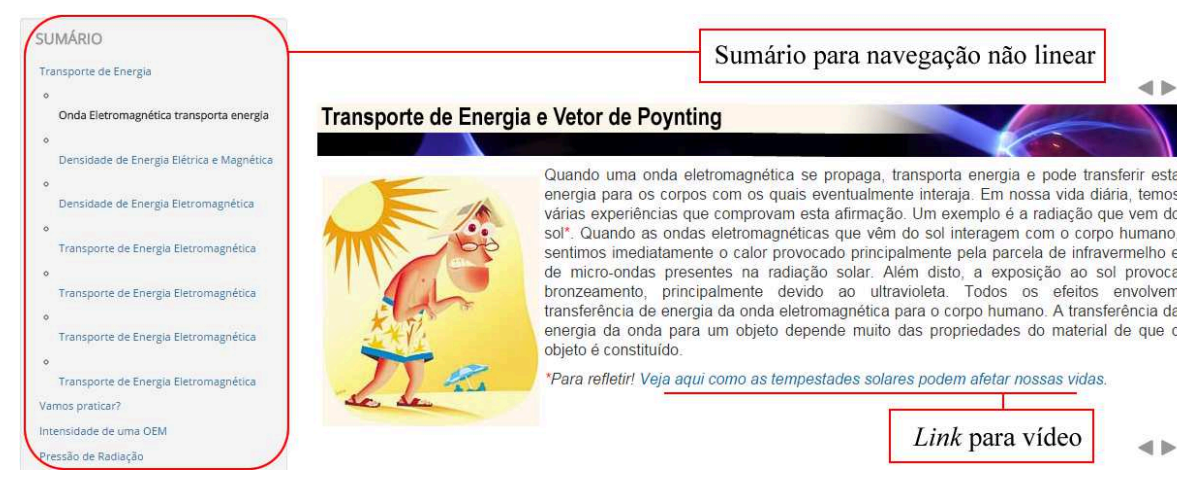

Fig. 1 - Exemplo de página de um dos Books criados para o conteúdo de ondas eletromagnéticas.

Foram criados três Books, todos obedecendo à mesma proposta, mas também trazendo as principais definições sobre o assunto, a linguagem matemática e as considerações dos aspectos científicos envolvidos.

Como estratégia de prática a ferramenta utilizada foi também a Tarefa. Numa das atividades os alunos eram convidados a assistir a um vídeo sobre Polarização de Micro-ondas e explicar o resultado das diferentes demonstrações apresentadas no vídeo com os conceitos vistos em sala. Trabalhou-se também a função de onda e as representações gráficas de grandezas como densidade de energia eletromagnética e potência.

Como estratégia de interação aluno-aluno elaborou-se uma atividade de pesquisa e a socialização de resultados para a avaliação entre pares. A ferramenta utilizada foi o Workshop (ou laboratório de avaliação) e trazia como abordagem temática a presença das ondas eletromagnéticas nas transmissões sem fio. $\mathrm{O}$ aluno por sua vez teria que realizar sua pesquisa e enviar para a avaliação dos pares. Tal avaliação foi conduzida por critérios previamente definidos, dentre eles: profundidade da abordagem, articulação de ideias, clareza na linguagem, seleção de referências (fontes) e fidelidade à proposta. Tais critérios obedeciam a uma escala onde a nota máxima para cada um poderia ser 10. A avaliação feita pelos pares depois foi validada pelo professor.

Foi desenvolvido também um fórum, que propunha a discussão sobre a sintonização dos canais de TV e a conexão deste tema cotidiano com o conteúdo em questão, e um glossário para os alunos socializarem definições sobre ondas eletromagnéticas. Foram disponibilizadas notas de aula, lista de exercícios, vídeos e simuladores como materiais de auxílio aos alunos.

A exemplo das ondas mecânicas propôs-se para as ondas eletromagnéticas estratégias e atividades cobrindo todos os eventos instrucionais do modelo adotado.

\section{3. Ótica}

Neste conteúdo propôs-se a criação de um conjunto de atividades compostas de: exercícios, leituras de textos, utilização de simuladores, vídeos e hiperlinks. Para tanto, foi es- 
colhida a ferramenta Lição. A ideia era aproveitar ao máximo as potencialidades dessa ferramenta. Assim, foram disponibilizadas algumas páginas de navegação com textos sobre difração, refração e reflexão.

Tais páginas conduziam os alunos para a realização de exercícios através simuladores. Para utilizá-los estabeleceram-se alguns parâmetros os quais eles teriam que lançar mão para observar os fenômenos. A atividade também sugeria a visualização de vídeos, a leitura de artigos científicos e a utilização de applets, para com isso diversificar as opções de linguagens e representações existentes.

Evidencia-se, mais uma vez que o Moodle oferece ferramentas importantes para a elaboração de atividades que envolvam um conjunto de elementos capazes de agrupar uma grande variedade de estratégias.

\section{Relatividade Restrita}

Os conteúdos de relatividade restrita (RR) abordados foram: o princípio da relatividade, o problema com a Mecânica Clássica, as transformações de Galileu e a luz, a busca pelo éter (o experimento de Michelson-Morley), os postulados da relatividade restrita, cinemática e dinâmica relativísticas, sistema de unidades convenientes e formalismo no espaço-tempo. Buscou-se um design instrucional oferecendo-se objetos de visualização, lançando mão de vídeos, simuladores e outros materiais didáticos digitais.

Para o evento de preparação visando-se investigar os conhecimentos prévios dos alunos através de questões propostas em uma Enquete. Assim o professor teria em mãos, a partir das respostas dos alunos, subsídios para a condução do conteúdo durante a sua execução, partindo dessas concepções e as adequando às concepções formais do conteúdo.

A estratégia de preparação também pode auxiliar o aluno na familiarização com o conteúdo que será trabalhado. Criou-se, então, um link para uma matéria jornalística intitulada "O Legado da Relatividade 3 " que abordava a importância da teoria da relatividade restrita para a humanidade. Elaborou-se um texto introdutório para apresentar os objetivos do material desenvolvido para discussão do conteúdo no AVA. Assim, os alunos poderiam, antes de participar das atividades e das leituras, saber quais conteúdos seriam abordados. Para motivação, foi disponibilizado no rótulo inicial do Moodle, um vídeo que mostrava brevemente e de maneira lúdica a questão da reformulação do conceito sobre tempo.

O modelo em questão orienta que sejam oferecidas atividades de aprendizagem variadas, para assim buscar atender à pluralidade de diferenças individuais dos alunos e, consequentemente, o alcance dos objetivos da disciplina. $\mathrm{O}$ conjunto de atividades proposto inclui leituras acompanhadas de recursos imagéticos (imagens estáticas e dinâmicas), materiais audiovisuais e atividades que incentivam a pesquisa (individual ou em grupo), a colaboração, como também atividades práticas que promovem a aplicação do conteúdo, estabelecendo re-

\footnotetext{
${ }^{3}$ STIX, G. Legado da Relatividade. Scientific American Brasil [s/d]. Disponível em: <http://www2.uol.com.br/sciam/reportagens/legado_da_relatividde.html>.
} 
levância ao assunto tratado e pretende-se que o conteúdo desperte nos alunos um significado pessoal ao propor o entendimento da sua importância para a sua área de atuação.

No que concerne ao evento de interação propôs-se que o conjunto de atividades desenvolvidas no material didático de RR assumisse uma forma mais intra e intertextual e multivocal onde as leituras foram articuladas com a realização de exercícios, vídeos, animações e imagens. Investiu-se, assim, na não linearidade do material de forma a deixar o aluno escolher o caminho a ser percorrido. Buscou-se incentivar a relação teoria-prática de maneira a aproximá-lo do tema estudado a partir de seus conhecimentos sobre o conteúdo e busca de conexão com exemplos práticos, incentivando-se também a pesquisa, de modo que percebessem na medida do possível aplicações dos conceitos estudados.

No evento de transferência tinha-se a possibilidade de verificar a capacidade de transformação e de aplicação do conteúdo em outras situações ou em contextos práticos. Propôs-se uma atividade de pesquisa desenvolvida na ferramenta Wiki que possibilita a criação de documentos de forma colaborativa, nos quais os participantes trabalham em grupo ou individualmente na construção de atividades que podem ser transformadas em páginas web. Ao ser indicada como ferramenta para a realização de uma atividade de transferência, a wiki assume a dimensão de ser um espaço adequado para que o aluno possa investir em suas contribuições de maneira mais aprofundada. Para se posicionar crítica e formalmente em um espaço de escrita colaborativa, este precisa ter construído um entendimento plausível do conteúdo para assim incluir suas ideias com base nos construtos adquiridos e intervir nas ideias e contribuições expressadas pelos outros participantes da atividade.

O fluxo de estratégias de aprendizagem desenvolvidas para este conteúdo encontrase melhor detalhado em Lacerda e Silva (2012) e em Lacerda (2013).

\section{Termodinâmica}

No conteúdo de termodinâmica, também houve a preocupação em aproximar os conceitos e as definições envolvidos à realidade do aluno. Por exemplo, a definição precisa do conceito de energia é muito difícil de ser elaborada, embora a maioria de nós tenha construído esse conceito de maneira não científica. Para essa aproximação, propôs-se aos alunos um Quiz em que eles pudessem responder o que já conheciam sobre termodinâmica e os fenômenos relacionados com trabalho, calor e energia.

As perguntas do Quiz foram desenvolvidas não apenas para identificar os conhecimentos dos alunos, mas também para que pudessem reconhecer e se familiarizar com o conteúdo que seria ministrado em seguida.

Outra atividade elaborada refere-se a um Glossário, sendo que nessa ocasião, ao invés de solicitar aos alunos que escolhessem os termos a serem definidos, a atividade sugeria um conjunto de termos e expressões relacionados à termodinâmica e os alunos escolhiam de um a três deles para apresentarem suas definições. Tem-se aqui outra opção de utilização do módulo Glossário já explorado em Ondas Mecânicas. 
Foram elaboradas também, duas atividades no módulo Lição, com proposições variadas de questões. Tais questões envolviam a leitura em artigos científicos e em páginas web, o uso de simuladores e a pesquisa para socialização em um fórum. A ideia era vincular um módulo de atividade a outro. Ao se propor dentro das atividades sugeridas na Lição que os alunos socializassem seus resultados no fórum tinha-se, desse modo a possibilidade da atividade individual, mas ao mesmo tempo a oportunidade de interação entre pares e com o professor.

\section{Mecânica Quântica}

O conteúdo de mecânica quântica foi o último conteúdo a ser ministrado no semestre. Os temas abordados foram radiação de corpo negro, efeito fotoelétrico cuja atividade foi obrigatória, o átomo de Bohr e a exploração de diferentes modelos atômicos, o experimento de Frank e Hertz que permitiu a validação da quantização de energia nos sistemas atômicos e o experimento realizado por Davisson e Germer para difração de elétrons que comprovou experimentalmente a existência de ondas de matéria propostas por De Broglie.

Decidiu-se criar um infográfico cujas informações pudessem direcionar os alunos para leituras e atividades a exemplo do que foi criado em RR, mas com uma linguagem visual diferente. A característica principal de um infográfico é a junção de pequenos textos com ilustrações explicativas e, geralmente, são usados onde a informação pode ser explicada de forma mais dinâmica. Nos ambientes virtuais de aprendizagem, especialmente no Moodle, é possível criá-los utilizando-se o recurso Rótulo. A Figura 2 apresenta como o conteúdo ficou disposto no tópico da disciplina.

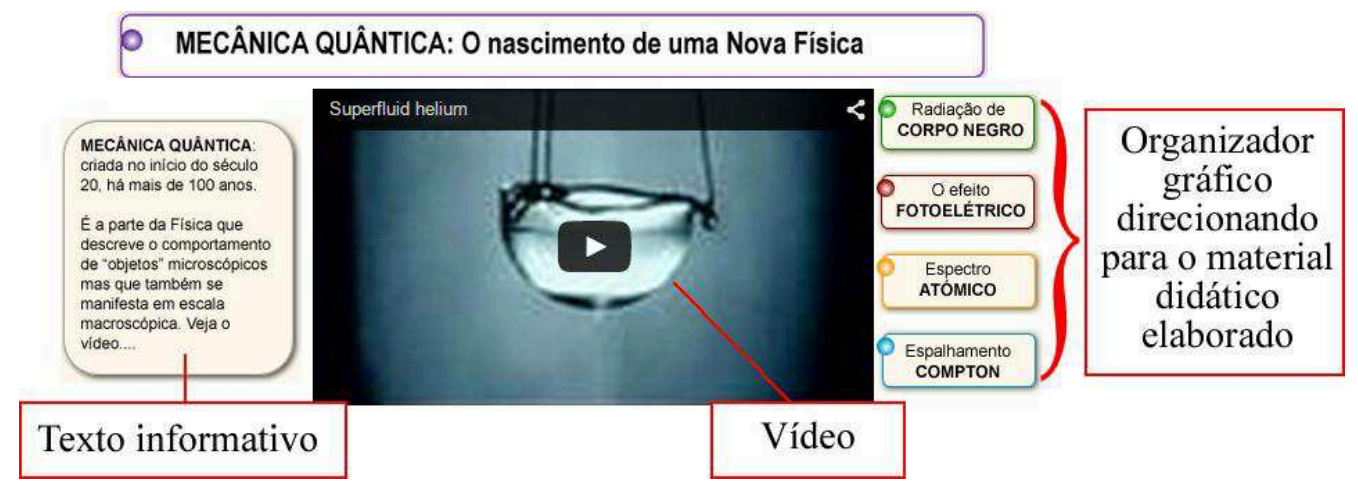

Fig. 2 - Imagem do infográfico criado no tópico destinado ao conteúdo de Mecânica Quântica.

Do lado direito da tela foi criado um organizador gráfico que direcionava os alunos aos Books desenvolvidos para o conteúdo. Do lado esquerdo um texto informativo sobre a temática que iria ser ministrada e que direcionava para o vídeo localizado na parte central do tópico. Tinha-se que na medida em que o aluno fosse "navegando" pelas informações descobrisse as principais questões relacionadas ao conteúdo. Assim, a identidade visual adotada foi igual à da apresentada no conteúdo de relatividade restrita. 
Os Books foram desenvolvidos com a finalidade de introduzir o conteúdo. Neles foram adicionados além de textos explicativos, vídeos e simuladores com atividades correlatas, que estimulavam os alunos a refletir e a responder as questões propostas nos questionários. É importante salientar que tanto os vídeos quanto os simuladores sugeridos traziam objetivos delineados para a sua utilização. Assim, o uso não era feito de forma exploratória, mas era guiado por uma orientação de parâmetros a serem observados pelos alunos e estes após a visualização deveriam responder às questões propostas. Desse modo, propôs-se o acesso aos Books e, em seguida, à realização das atividades. Destaca-se que o aluno tinha a opção de acessar o material de leitura ou ir diretamente para a realização da atividade.

\section{Avaliação a partir da participação dos alunos}

A participação dos alunos pode ser coletada a partir dos mecanismos do Moodle que fornecem os dados de acesso, desempenho e participação nas atividades desenvolvidas no AVA, o que fornece uma quantidade de dados riquíssima. No entanto, julga-se pertinente evidenciar resultados referentes a alguns dos conteúdos trabalhados, no que concerne (i) à participação nas atividades; (ii) ao desempenho dos alunos na realização das tarefas e (iii) ao acesso dos alunos ao material didático disponível. Para tanto, os dados foram codificados e sistematizados em planilhas eletrônicas através das quais foi possível criar tabelas e gráficos para a análise.

\section{(i) Participação nas atividades}

Destacam-se nesse indicador os conteúdos de ondas mecânicas, ondas eletromagnéticas e relatividade restrita.

A Tabela 1 apresenta a participação dos alunos nas atividades obrigatórias e não obrigatórias destes conteúdos. No conteúdo de Ondas Mecânicas (OM), foram propostas como atividades duas (2) Tarefas de envio de arquivo (Tarefa I e Tarefa II), 1 Glossário, 1 atividade de pesquisa e a socialização na ferramenta Base de Dados. Todas consideradas como atividades obrigatórias. As atividades não obrigatórias compreendiam a participação voluntária na Lição que foi desenvolvida no formato de exercício e em um questionário proposto logo após a leitura realizada nos Books. É possível observar que dos 34 alunos matriculados da disciplina $77 \%$ participaram da atividade de pesquisa, $68 \%$ na proposta desenvolvida no Glossário, $76 \%$ participaram da Tarefa I e $75 \%$ da Tarefa II. No que concerne à participação dos alunos nas atividades obrigatórias, propostas para o conteúdo de Ondas Eletromagnéticas (OEM), observa-se também bons resultados nesse aspecto. Propôs-se a eles que respondessem um questionário (Q1) como estratégia de preparação para identificar os seus conhecimentos sobre OEM. Durante o processo, o mesmo questionário (Q1.1) foi retomado com a finalidade de analisar a aprendizagem sobre o conteúdo. Dos 34 alunos 79\% participaram de Q1 e 71\% participaram de Q1.1. Outra atividade obrigatória foi realizada na ferramenta Workshop (ava- 
liação entre pares), nesse caso, $68 \%$ dos alunos participaram efetivamente da estratégia proposta.

Tabela 1 - Resultados da participação dos alunos nas atividades de Ondas Mecânicas, Eletromagnéticas e Relatividade Restrita.

\begin{tabular}{|c|c|c|c|}
\hline Conteúdo & Atividade & Obrigatória & Participação (\%) \\
\hline \multirow{6}{*}{ Ondas Mecânicas } & Base de Dados & \multirow{4}{*}{ Sim } & 77 \\
\hline & Glossário & & 68 \\
\hline & Tarefa I & & 76 \\
\hline & Tarefa II & & 75 \\
\hline & Questionário & \multirow{2}{*}{ Não } & 92 \\
\hline & Lição & & 73 \\
\hline \multirow{3}{*}{$\begin{array}{l}\text { Ondas Eletromagnéti- } \\
\text { cas }\end{array}$} & Q1 & \multirow{3}{*}{ Sim } & 79 \\
\hline & Q1.1 & & 71 \\
\hline & Workshop & & 68 \\
\hline \multirow{12}{*}{ Relatividade Restrita } & Q1 & \multirow{10}{*}{ Não } & 9 \\
\hline & Q2 & & 33 \\
\hline & Q3 & & 27 \\
\hline & Q4 & & 18 \\
\hline & $\mathrm{Q} 5$ & & 9 \\
\hline & Q6 & & 8 \\
\hline & Q7 & & 7 \\
\hline & $\mathrm{Q} 8$ & & 7 \\
\hline & E1 & & 33 \\
\hline & E2 & & 2 \\
\hline & Atividade 1 & \multirow{2}{*}{ Sim } & 74 \\
\hline & Atividade 2 & & 56 \\
\hline
\end{tabular}

Fonte: Elaborado pelos autores.

Os resultados apresentados nessa circunstância específica desmistificam a hipótese de que os alunos possivelmente só participariam de atividades obrigatórias, já que é possível observar que não há uma diferenciação quanto à participação em atividades obrigatórias e não obrigatórias. No questionário, por exemplo, que não era uma atividade obrigatória, $92 \%$ dos alunos participaram efetivamente, assim como na lição que teve $73 \%$ de participação.

Em relação à participação nas atividades desenvolvidas para o conteúdo de Relatividade Restrita no semestre 2012.1, como atividades obrigatórias se propôs a formação de grupos entre os alunos para que resolvessem algumas questões propostas logo após assistirem a um vídeo (Atividade I) e a outra atividade propunha a interação usando-se um applet e, em 
seguida, a resolução de questões correlatas. Assim 74\% dos alunos participaram da Atividade I e 56\% da Atividade II. As demais atividades disponibilizadas tinham caráter não obrigatório e é possível apresentar como se deu a livre participação nessas atividades. A Tabela 1 apresenta os resultados da participação dos alunos nos 8 questionários $(\mathrm{Q} 1, \mathrm{Q} 2, \mathrm{Q} 3, \ldots, \mathrm{Q} 8)$ e nas enquetes, de preparação (E1) elaborada com o objetivo de investigar os conhecimentos dos alunos sobre o conteúdo e na que havia uma questão dissertativa integrada a um dos Books (E2). Pode-se concluir que não houve atividade não obrigatória que não fosse realizada. A flutuação é visível e reflete a maior ou menor complexidade do que foi proposto. Vale destacar que se atinge o objetivo de buscar atender à pluralidade de sujeitos envolvidos numa turma.

Ainda como atividade obrigatória foi proposta a participação na Wiki obedecendo-se a 6 critérios de avaliação. Dos 34 alunos da disciplina 11 (32\%) alunos participaram. Para avaliar a atividade lançou-se mão dos critérios combinados e observaram-se as contribuições. Para tanto, desenvolveu-se uma escala de pontos os quais serviam para orientar na avaliação. Desse modo as contribuições dos alunos recebiam pontos positivos (+) quando atendiam ao critério solicitado e pontos negativos (-) quando havia ausência de elementos de cada critério na sua contribuição. $\mathrm{Na}$ análise estabeleceu-se que o aluno que obtivesse até 1 ponto negativo (-) teria sua contribuição considerada boa, o aluno que obtivesse até 3 pontos negativos sua contribuição seria considerada razoável e aquele aluno com pontos negativos acima de 3 , ou seja, de 4 até 6 pontos negativos sua contribuição seria considerada ruim. A Tabela 2 apresenta a organização dos dados para a avaliação da Wiki.

Tabela 2 - Resultado das contribuições dos alunos na Wiki de Relatividade Restrita.

\begin{tabular}{|c|c|c|c|c|c|c|c|c|c|c|c|}
\hline \multirow[t]{2}{*}{ Critério } & \multicolumn{11}{|c|}{ Aluno } \\
\hline & $\mathbf{A 1}$ & A2 & A3 & A4 & A5 & A6 & A7 & A8 & A9 & A10 & A11 \\
\hline $\begin{array}{l}\text { 1) O aluno foi capaz de contribuir } \\
\text { com um aprofundamento sobre o } \\
\text { conteúdo? }\end{array}$ & + & - & + & + & - & + & + & + & - & + & - \\
\hline $\begin{array}{l}\text { 2) O aluno correlacionou o conteúdo } \\
\text { com a sua vida prática? }\end{array}$ & + & - & - & - & - & - & - & + & - & + & + \\
\hline $\begin{array}{l}\text { 3) O aluno conseguiu estabelecer } \\
\text { conexões com outras fontes? }\end{array}$ & + & + & + & + & - & - & + & + & - & + & + \\
\hline $\begin{array}{l}\text { 4) O aluno foi capaz de sintetizar as } \\
\text { informações? }\end{array}$ & + & + & + & + & + & + & - & + & - & + & - \\
\hline $\begin{array}{l}\text { 5) A contribuição do aluno trouxe } \\
\text { linguagem característica da web? }\end{array}$ & + & + & + & + & - & - & + & + & - & + & + \\
\hline $\begin{array}{l}\text { 6) } \mathrm{O} \text { aluno fez intervenções perti- } \\
\text { nentes no texto do colega? }\end{array}$ & - & - & - & - & - & + & - & + & + & - & - \\
\hline Total $(+)$ & 5 & 3 & 4 & 4 & 1 & 3 & 3 & 6 & 1 & 5 & 3 \\
\hline Total (-) & 1 & 3 & 2 & 2 & 5 & 3 & 3 & $\mathbf{0}$ & 5 & 1 & 3 \\
\hline
\end{tabular}

Fonte: Elaborado pelos autores. 
Observa-se na Tabela 2 que dentre os alunos que participaram da Wiki, 3 tiveram suas contribuições consideradas como boa, enquanto que 6 dos 11 alunos apresentaram contribuições razoáveis e 2 obtiveram avaliação como ruim. Os critérios 1, 3, 4 e 5 foram os critérios que mais apresentaram pontos positivos. No critério 1 dos 11 alunos participantes 7 trouxeram em suas contribuições aprofundamento sobre o conteúdo. No critério 3, a maioria dos alunos conseguiu estabelecer conexões com outras fontes. Nos critérios 4 e 5 é possível observar que os alunos conseguiram sintetizar as informações, bem como diversificar a forma de apresentação, contribuindo com linguagens características da web, tais como vídeos, imagens e hiperlinks. No entanto, foi possível observar também que os alunos não obtiveram bons resultados quanto às intervenções no texto dos colegas, estas quando ocorriam não traziam construtos suficientes a serem considerados.

\section{(ii) Desempenho dos alunos}

Destacam-se nesse indicador os conteúdos de ondas mecânicas, ótica, ondas eletromagnéticas, relatividade restrita e termodinâmica.

Para analisar o desempenho dos alunos nas atividades realizadas no Moodle, principalmente, aquelas em que a própria ferramenta oferece um feedback automático, tais como Questionário, Lição e Glossário, utilizou-se a seguinte escala: baixo, médio e alto. Para os alunos com resultados entre $0 \%$ e $29 \%$ considerou-se seu desempenho baixo, para aqueles com resultados entre $30 \%$ e $59 \%$ considerou-se seu desempenho médio e aqueles alunos com resultados entre $60 \%$ e $100 \%$ seu desempenho foi considerado alto. Na atividade obrigatória desenvolvida na ferramenta Lição elaborada para o conteúdo de Ótica observou-se que dos $62 \%$ dos alunos que participaram e responderam aos exercícios da lição, todos obtiverem desempenho alto, ou seja, os resultados ficaram entre $60 \%$ e $100 \%$. Nas atividades do conteúdo de ondas mecânicas, os alunos tiveram alto desempenho, no entanto, nas atividades de ondas eletromagnéticas, apresentaram baixo desempenho. Na Tabela 3 é possível observar os resultados concernentes ao desempenho nas atividades obrigatórias desses conteúdos.

Tabela 3 - Desempenho dos alunos em atividades de OM e OEM.

\begin{tabular}{|l|c|c|c|c|c|c|c|c|}
\hline \multirow{3}{*}{ Desempenho } & \multicolumn{8}{|c|}{ Atividades } \\
\cline { 2 - 10 } & Ondas Mecânicas & \multicolumn{2}{|c|}{ Ondas Eletromagnéticas } & \multicolumn{3}{c|}{ Termodinâmica } \\
\cline { 2 - 10 } & Q1 & Lição & Workshop & Q1 & Q2 & Quiz & Lição 1 & Lição 2 \\
\hline Baixo & 0 & 1 & 20 & 27 & 23 & 0 & 3 & 13 \\
\hline Médio & 1 & 0 & 3 & 0 & 1 & 2 & 7 & 1 \\
\hline Alto & 30 & 24 & 11 & 7 & 10 & 28 & 7 & 0 \\
\hline Total de alunos & $\mathbf{3 1}$ & $\mathbf{2 5}$ & $\mathbf{3 4}$ & $\mathbf{3 4}$ & $\mathbf{3 4}$ & $\mathbf{3 0}$ & $\mathbf{1 7}$ & $\mathbf{1 4}$ \\
\hline
\end{tabular}

Fonte: Elaborado pelos autores. 
Observa-se que no questionário de ondas mecânicas (Q1) dos 32 alunos que completaram a atividade, 30 alunos tiveram alto desempenho, o que corresponde a $89 \%$ do total da turma. No exercício realizado através da ferramenta Lição 24 alunos entre os 25 que responderam à atividade tiveram alto desempenho, o que corresponde a $71 \%$ do total da turma. Nas atividades desenvolvidas no conteúdo de OEM a participação dos alunos pode ser considerada boa, no entanto, quanto ao desempenho destaca-se o baixo desempenho. Na atividade Workshop, dos 34 alunos que realizaram a atividade (100\% da turma), 11 tiveram desempenho alto, 3 tiveram desempenho médio e 20 apresentaram desempenho baixo.

É importante considerar que a quantidade de atividades propostas no AVA deve ser comedida, pois pode se tornar cansativo ao mesmo tempo em que pode convergir com outros afazeres dos alunos relativos a outras disciplinas do seu curso. No entanto, a equipe multidisciplinar deve atentar para a elaboração de atividades objetivas e que criem ambiências ao mesmo tempo motivadoras, mas que estimulem melhorias na aprendizagem. Nesse sentido, destacam-se as atividades elaboradas para o conteúdo de RR, que embora não apresente um número expressivo no que concerne ao desempenho, demonstra o engajamento do aluno no que tange à participação.

Nas atividades desenvolvidas para o conteúdo de Termodinâmica o desempenho dos alunos ficou balanceado conforme Tabela 3. No Quiz, dos 30 alunos que o responderam 28 tiveram desempenho alto. No entanto, nos exercícios e atividades propostas nas lições, o desempenho pode ser considerado médio. Na Lição 1 dos 17 alunos que participaram 82\% tiveram desempenho de médio para alto. Na Lição 2 dos 14 alunos participantes, 13 tiveram baixo desempenho.

A apresentação dos dados desse indicador, cujos resultados apontam para o desempenho dos alunos, podem trazer apontamentos para a possibilidade de avaliação em um AVA. Nessa perspectiva, é possível observar que nas atividades desenvolvidas em ferramentas que possuem feedback automático, os dispositivos existentes possibilitam mapear o processo de construção singular de cada participante. Contudo, ainda faltam mecanismos que auxiliem o professor para a avaliação nas ferramentas como fóruns, Wiki e em questões dissertativas. Entretanto, os resultados possíveis de ser dimensionados, a partir desses mecanismos, podem auxiliar o professor na condução do processo, este pode lançar mão desses dados e fornecer feedback ao grupo de alunos ou individualmente.

Outra maneira de observar a participação dos alunos pode ser encontrada no que concerne aos acessos dos alunos, como será apresentado no item a seguir.

\section{(iii) Acesso ao material didático}

Destacam-se nesse indicador os conteúdos de ondas mecânicas, ótica, ondas eletromagnéticas, relatividade restrita, termodinâmica e mecânica quântica. Apresenta-se o acesso dos alunos aos Books e aos recursos de apoio disponibilizados no Moodle, tais como notas de 
aula, simuladores e listas de exercícios. Contudo, pretende-se também demonstrar como se deu o acesso, como os alunos percorrem o material.

De início apresenta-se a média aritmética de acessos dos alunos a alguns materiais de leitura e de apoio disponíveis no Moodle. Na Tabela 4 a seguir é possível observar que nos Books desenvolvidos para os conteúdos de ondas eletromagnéticas (OEM) e ondas mecânicas (OM) a média de acessos foi de 59\% do total de alunos matriculados. As listas de exercícios tiveram média de $66 \%$ de acessos, os simuladores $51 \%$ de acessos e as notas de aula $71 \%$.

Tabela 4 - Média de acesso dos alunos aos Books e aos recursos de apoio aos conteúdos.

\begin{tabular}{|c|c|c|}
\hline Recurso & Conteúdos & Média de Acessos \\
\hline Books & OEM/OM & $59 \%$ \\
\hline Listas de exercícios & OM/OEM/QUÂNTICA/ÓTICA & $66 \%$ \\
\hline Simuladores & OM/QUÂNTICA/ÓTICA & $51 \%$ \\
\hline Notas de aula & OM/OEM/QUÂNTICA/ÓTICA/TERMO & $71 \%$ \\
\hline Vídeos & OEM & $66 \%$ \\
\hline
\end{tabular}

Fonte: Elaborado pelos autores.

Em linhas gerais, é possível observar no que concerne ao conteúdo de ondas mecânicas que a participação dos alunos foi expressiva, seja nas atividades obrigatórias como também nas atividades não obrigatórias o que demonstra engajamento e boa receptividade ao design instrucional desenvolvido para a disciplina. E vale destacar que se trata do conteúdo trabalhado no início do semestre, quando os alunos estão menos atribulados com a própria disciplina e com as demais em que estão matriculados. Em síntese, é possível considerar que os alunos buscam acessar os materiais complementares que são disponibilizados no AVA.

A seguir, apresenta-se um exemplo de como observar a navegação dos alunos e o percurso feito nas páginas do material didático desenvolvido. Na ferramenta Lição que tem como característica, além da elaboração de páginas de questões, a criação de páginas de conteúdos numa estruturação não linear, foi possível identificar o acesso dos alunos nas páginas das Lições desenvolvidas para o conteúdo de relatividade restrita. Foram criadas 3 lições com o objetivo de estimular a leitura laçando mão de linguagem diversificada, no qual se vinculavam textos, vídeos, simuladores, hiperlinks e imagens.

$\mathrm{Na}$ Tabela 5 é possível identificar os acessos dos alunos às páginas das três lições. A primeira linha, em cinza, de cada lição fornece o número total de alunos que acessaram e o número total de páginas de conteúdo de cada uma. As demais linhas fornecem a distribuição de alunos de acordo com o número de páginas acessadas. Observa-se, por exemplo, que na Lição 1 foram criadas um total de 22 páginas de conteúdo. Dos 34 alunos da disciplina, 24 deles acessaram essa lição, dos quais 21 acessaram todas as páginas, 2 alunos acessaram 15 páginas e 1 aluno acessou 4 páginas. Não é possível, saber exatamente o tipo de exploração 
feito pelo aluno, o tempo real que cada um se ateve em cada uma delas e o que mais chamou atenção, mas trata-se certamente de um indicativo de seu interesse pelo material disponibilizado. Na Lição 2 foram criadas 20 páginas de conteúdo. Nesse caso, destaca-se que 21 alunos a acessaram, dos quais 13 acessaram todas as páginas, os demais acessos estão apresentados na Tabela 5. A Lição 3, por sua vez contém 8 páginas e foi acessada integralmente por 15 alunos, os demais acessos estão também explicitados apresentados na Tabela 5.

Tabela 5 - Percurso dos alunos nas páginas da ferramenta Lição do conteúdo de RR.

\begin{tabular}{|c|c|c|}
\hline Atividade & Número de Alunos que acessaram & Número de páginas por aluno \\
\hline \multirow{4}{*}{ Lição 1 } & 24 & 22 \\
\cline { 2 - 3 } & 21 & 22 \\
& 2 & 15 \\
& 1 & 4 \\
\cline { 2 - 3 } & 21 & 20 \\
\hline \multirow{4}{*}{ Lição 2 } & 13 & 20 \\
& 1 & 17 \\
& 2 & 12 \\
& 1 & 7 \\
& 1 & 5 \\
& 1 & 4 \\
& 21 & 2 \\
\hline \multirow{4}{*}{ Lição 3 } & 15 & 8 \\
& 1 & 8 \\
& 1 & 6 \\
& 3 & 5 \\
& 1 & 4 \\
\hline
\end{tabular}

Fonte: Elaborado pelos autores

A disciplina foi desenhada também com atividades interdependentes, ou seja, para a realização de um exercício em um questionário, por exemplo, o aluno deveria antes fazer a leitura no Book e, em seguida, realizar um experimento proposto em um simulador ou applet. A Tabela 6 a seguir apresenta um exemplo desse formato de atividade proposto no conteúdo de Mecânica Quântica. Destaca-se que no AVA pode ser atribuída ao aluno a liberdade de escolher os caminhos os quais ele quer percorrer, assim os resultados a seguir, demonstram bem esse aspecto. Nas atividades 1 e 2 era proposto aos alunos acessar o Book para leitura e compreensão do conteúdo, em seguida, realizar um experimento em um simulador e depois a realizar um exercício desenvolvido em um questionário. Na Tabela 6 é possível observar que na Atividade 1, a mesma quantidade de alunos percorreu todo o caminho proposto, ou seja, dos $35 \%$ de alunos que participaram da Tarefa todos acessaram o Book, realizaram o experimento e responderam ao questionário. No entanto, na Atividade 2 a mesma quantidade de 
alunos que acessou o Book e realizou o experimento, não foi a mesma que realizou o exercício proposto.

Tabela 6 - Participação dos alunos em atividades propostas que integram diferentes recursos.

\begin{tabular}{|c|c|c|c|c|c|}
\hline \multicolumn{3}{|c|}{ Atividade1 } & \multicolumn{3}{c|}{ Atividade 2 } \\
\hline Book & Simulador & Exercício & Book & Simulador & Exercício \\
\hline $35 \%$ & $35 \%$ & $35 \%$ & $18 \%$ & $18 \%$ & $12 \%$ \\
\hline
\end{tabular}

Fonte: Elaborado pelos autores.

Outro ponto a destacar, no que concerne aos questionários, é a possibilidade de ser criado um banco de questões para a disciplina. Assim, foram criados dois bancos de questões que em seguida foi disponibilizado através da ferramenta Questionário para os alunos. As questões foram agrupadas por conteúdo e o Questionário foi liberado para auxiliar os alunos que gostam de se prepararem para as provas a partir da resolução de exercícios de provas anteriores.

No que concerne à participação dos alunos, considera-se que foi efetiva. No entanto, destaca-se como um ponto a ser melhorado, mais precisamente, estimulado nos alunos é a interação no AVA. Foi possível perceber que nos fóruns, assim como também nas atividades que exigiam a colaboração, a interação foi quase muito aquém do esperado. Pode-se constatar a falta de hábito em participar desse tipo de estratégia em uma disciplina e por não se sentirem confortáveis em expor seu ponto de vista por escrito para o grupo. Faz-se importante, então, no DI prever atividades que os auxiliarão a interagirem e a ganharem essa confiança. Mas, pode-se entender também que envolve mudanças de hábitos e de uma nova cultura a respeito do processo de ensino e aprendizagem que não se conquista de uma hora para a outra. É um processo lento e gradativo.

\section{Considerações finais}

O artigo buscou apresentar propostas de integração de ambiente virtual de aprendizagem no ensino presencial de física como possibilidades de desenvolvimento de práticas pedagógicas através desses espaços. Constatou-se que o design instrucional, a partir dos elementos e princípios que o constituem pode fazer emergir a interação entre professor-alunoconteúdo, o que exige a adoção de estratégias e/ou eventos que auxiliam a adequação aos objetivos de ensino visando melhorias na aprendizagem. Infere-se que a aplicação da proposta foi bem-sucedida, o que permitiu alcançar os objetivos definidos.

Diante do exposto considera-se que é possível desenvolver o design instrucional do conteúdo programático de uma disciplina presencial em um ambiente virtual de aprendizagem, propiciando interatividade, atendendo às diferenças individuais dos alunos para possibilitar melhorias no ensino e na aprendizagem. É possível observar que o material didático de- 
senvolvido buscou a integração entre professor-aluno-conteúdo, orientando-se e apoiando-se adequadamente nas proposições metodológicas da disciplina em questão. Reforça-se ainda que desenhar uma disciplina em um AVA para o ensino presencial demanda a composição de uma equipe multidisciplinar, que pode ser formada por diferentes profissionais das áreas da tecnologia, da comunicação e das licenciaturas, particularmente, aqueles que consigam justapor criticamente o olhar técnico ao olhar pedagógico.

Considera-se também, que o design instrucional de uma disciplina presencial não é método prescritivo, mas uma proposição aberta a metodologias diferenciadas, capazes de oferecer situações de aprendizagem que busquem desenvolver múltiplas competências cognitivas, habilidades e atitudes.

O material resultante dessa investigação buscou estabelecer múltiplas conexões com o espaço virtual e garantir a articulação de cada material com os demais do mesmo conjunto, furtando-se de estabelecer uma proposta fragmentada e descontextualizada do programa da disciplina. O Moodle por sua vez, possibilitou a integração de várias linguagens e de vários suportes midiáticos, no entanto, demonstrou não ser tão amigável quanto parece, quando não permite a criação de um material didático mais robusto, quando engessa o layout não permitindo avançar muito nas questões do discurso visual.

É possível inferir que um princípio fundamental no emprego da tecnologia na educação é começar atendendo às necessidades dos estudantes, não somente dos professores. $\mathrm{O}$ objetivo deve ser usar a tecnologia para criar um ambiente afetivo e estimulante para o estudo, onde o estudante se encontra. Ao se propor metodologias inovadoras é preciso discutir com novos paradigmas.

A partir da escolha de um modelo concebido à luz de diversas bases teóricas, tornou possível organizar e estruturar o material didático desenvolvido e, assim, expandir a sala de aula para o espaço virtual, flexibilizando-a. Não se trata de substituir os modelos convencionais de fazer educação. Trata-se de introduzir a cultura digital no ambiente educativo, com o intuito de promover a criatividade, a autonomia e a autoria dos envolvidos, na busca por estimular um processo de aprendizagem motivador e de fato permanente.

É preciso promover o debate e apontar possibilidades de uso, assim entende-se que é possível questionar a rigidez dos padrões e tornar a sala de aula mais flexível. Ganha o ensino de física, ganham professores e alunos e principalmente abrem-se novos horizontes para a Educação.

\section{Agradecimentos}

A produção desse material teve financiamento do MEC/CAPES no âmbito do edital "O Uso da Tecnologia da Informação e Comunicação na Formação dos Alunos do Curso de Física Presencial" (Edital No 15 de 23 de março de 2010). 


\section{Referências}

ALLY, M. Foundations of educational theory for online learning. In: ANDERSON, T. e ELLOUMI, F. Theory and Practice of Online Learning. Canadá, 2004.

FELIPE, G.; BARROSO, M. F; PORTO, C. M. Simulações computacionais no ensino de relatividade restrita. In: SIMPÓSIO NACIONAL DE ENSINO DE FÍSICA, XVI, 2005, Rio de Janeiro. Anais... Disponível em: <http://www.if.ufrj.br/ marta/aplicativos/2005-snef16aplicat-relat.pdf >. Acesso em: 08 ago. 2011.

JONG, T. Cognitive load theory, educational research and instructional design: some food for thought. Instr. Sci., v. 38, p. 105-134, 2010.

LACERDA, A. L. Contribuições do design instrucional ao ensino presencial de física apoiado por ambiente virtual de aprendizagem. 2013. Dissertação (Mestrado em Educação Científica e Tecnológica) - Universidade Federal de Santa Catarina, Florianópolis. Disponível em: <http://www.bu.ufsc.br/teses/PECT0195-D.pdf > Acesso em: 13 ago. 2013.

LACERDA, A. L; SILVA, T. Design instrucional e o ensino de relatividade restrita. In: ENCONTRO DE PESQUISA EM ENSINO DE FÍSICA, XIV, 2012, Maresias. Atas... Disponível em:<http://www.sbf1.sbfisica.org.br/eventos/epef/xiv/sys/resumos/T0331-1.pdf>.

Design instrucional de relatividade restrita em ambiente virtual de aprendizagem. In: SIMPÓSIO NACIONAL DE ENSINO DE FÍSICA, XX, 2013, São Paulo. Atas... Disponível em: <http://www.sbf1.sbfisica.org.br/eventos/snef/xx/sys/resumos/T1069-1.pdf>.

LEMES, T. C.; REZENDE JÚNIOR, M. F. A física moderna e contemporânea nos cursos de engenharia do Brasil: cenário atual e perspectivas. Revista de Ensino de Engenharia, v. 30, n. 2, p. 24-34, 2011. Disponível em: <http://www.upf.br/seer/index.php/ree/article/view/888/1604 >Acesso em: 14 mar. 2013.

MEDEIROS, A.; MEDEIROS, C. F. Possibilidades e limitações das simulações computacionais no ensino da Física. Revista Brasileira de Ensino de Física, São Paulo, v. 24, n. 2, p. 77-86, jun. 2002. Disponível em: <http://www.sbfisica.org.br/rbef/pdf/v24_77.pdf>. Acesso em: 06 out. 2012.

MORAN, J. M. Novos desafios na educação: a internet na educação presencial e virtual. In: PORTO, T. M. E (Org.). Saberes e Linguagens de educação e comunicação. Pelotas: Editora da UFPel, 2001. p. 19-44. Disponível em: <http://www.eca.usp.br/prof/moran/novos.htm>. Acesso em: 13 mai. 2011.

PERFOLL, A. P.; REZENDE JUNIOR, M. F. A física moderna e contemporânea e o ensino de engenharia: contexto e perspectivas. In: CONGRESSO BRASILEIRO DE ENSINO DE 
ENGENHARIA, 36, 2006, Passo Fundo. Anais... Passo Fundo: Ed. Universidade de Passo Fundo, set 2006. Disponível em:

<http://www.abenge.org.br/CobengeAnteriores/2006/artigos/11_97_581.pdf >. Acesso em: 14 mai. 2012.

SANTOS, L. M. A.; TAROUCO, L. M. R. A importância do estudo da teoria da carga cognitiva em uma educação tecnológica. Novas Tecnologias na Educação. Porto Alegre, v. 5 n. 1, jul. 2007. Disponível em: <http://www.cinted.ufrgs.br/ciclo9/artigos/2dLeila.pdf>. Acesso em: 22 abr. 2011.

SILVA, T.; BARROSO, M. F. Fenômenos astronômicos e ensino a distância: produção e avaliação de materiais didáticos. In: ENCONTRO DE PESQUISA EM ENSINO DE FÍSICA ENPEC, 11, 2008, Curitiba. Anais... Disponível em:

<http://www.if.ufrj.br/ marta/artigosetal/2008-epef11-astron.pdf>. Acesso em: 16 mar. 2013.

SOUSA, C. A; DE BASTOS, F. P.; ANGOTTI, J. A. P. As mídias e suas possibilidades: desafios para o novo educador. In: ANGOTTI, J. A. P.; REZENDE, M. F. Prática de Ensino de Física. Florianópolis, LAED/UFSC, 2001. Disponível em:

<http://www.ced.ufsc.br/men5185/artigos/angotti_as_midias.htm >Acesso em: 26 abr. 2011.

SWELlER, J.; van MERRIENBOER, J. J. G.; PASS, F. G. W. C. Cognitive Architecture and Instructional Design. Educational Psychology Review, v. 10, n. 3, p. 251-296, 1998. 